\title{
A Modular Approach in Teaching Thyristor Rectifiers with Equation-Oriented Softwares
}

\author{
A. O. Di Tommaso, F. Genduso, and R. Miceli, member, IEEE \\ DEIM, Department of Energy, Information engineering and Mathematical modeling \\ University of Palermo. \\ email: antoninooscar.ditommaso@ unipa.it, fabio.genduso@unipa.it, rosario.miceli@unipa.it
}

\begin{abstract}
This article is devoted to some issues of teaching power electronics in university courses. In the modern education system the students are expected to be no longer subject of passive learning, but that, within a certain extent, they collaborate in their training interactively with the teacher to develop the applications and the topics of the studied framework. For this purpose, this article presents a modular approach for teaching module regarding three-phase thyristor rectifiers.

A simulator based on the MATLAB equation solver has been developed by considering the detailed physical operation of such converters. In particular, the realized simulator takes various aspects into account, including continuous and discontinuous, commutation, its effect on the supply network and control parameters variations.

The software modularity considers a very simple starting point and allows the extension to more complex topologies (bidirectional converters, cycloconverters and so on), maintaining always the same level of interaction with the students so that they can increase their skills and develop their own self-learning capability and self-training strategies.
\end{abstract}

Index Terms-Modular teaching approach, Power electronics, converters, Equation oriented simulation software.

\section{INTRODUCTION}

The modern teaching of power electronics uses nowadays multimedia aids to improve students learning capability and better understanding of the various phenomena involved in energy conversion [1]-[4]. In particular, the greater availability of simulation softwares, characterized by an high degree accuracy, makes these multimedia aids more suitable than in the past, whereas laboratory experiments, even if always necessary, can be limited and can result less effective due to a possible high number of students. Furthermore, experimental equipments are very expensive and do not allow always a complete overview of the electrical quantities involved in power conversion [2], [5]-[7].

Moreover, laboratory experiments expose, sometimes, students to the risks of electric shock and injuries. For these reasons each laboratory experience must be conceived and planned carefully. A didactic laboratory should be expressly dedicated to the works and the assignments of the students with a previous and careful consideration for all the safety issues by considering that students can not be considered as trained personal.

In the case of a learning object [8] realized with simulation tools, each student can act, instead, in a totally safe environment. The student can also examine all the operational aspects, both for single devices and for complex static energy conversion systems in general, interfacing with it in interactive mode in order to test the influence of circuit and control system parameters suddenly verifying their weight both in transient and at steady state.

Nowadays simulation softwares used in electrical engineering are essentially divided of two families:

- circuit-oriented softwares;

- equation-oriented softwares.

Circuit oriented simulation tools allow to realize the simulation of a converter with great immediacy, simply by using schematics of the system under analysis [9]. Equation oriented tools require instead the knowledge of the system dynamics differential equations [5], [10], [11]. The former can suffer for convergence problems of numerical integration algorithms, but they have the main advantage that the system state space equations are determined automatically and are more user friendly than the latter [1], [2], [12], [13].

Equation-oriented tools can be more or less accurate in virtue of the system complexity, but they are certainly faster and let to achieve a good trade-off between the accuracy of the result and the simulation speed. Equation oriented softwares are very often used as tools of assisted design [14], [15] for complex system with a wide variety of electro-mechanical components [15]-[20], for the simulation of power electronics in many different operating conditions, faulty included [21] [24] and for very complex and large electrical system with various degrees of extension and interconnection [20], [22], [24]-[26].

Furthermore, they can stimulate the students to grow-up their skills in system modeling and problem analysis, which will be very important for their future professional life.

Self-training educational is a modern teaching vision in which the students are no longer passive subject, but they actively works on various aspects of their education, with a clear knowledge of the specific goals to be achieved [27]. This particular issue, discussed since many time, has been recently considered in the context of power electronics by Prof. N. Mohan in [28] where he considered, for the first time, an educational approach based on the "building blocks" concept.

A building block can be considered as a stand-alone unit able to represent a simple system or a part of it. A building block is reusable to achieve more complex structures too. From the educational point of view, the building blocks usage 
assumes the consideration of some simple basic problems, thanks to which more complex problems can be traced later.

In this scenario, and considering system modeling skills that the students must develop, the Authors have preferred equation-oriented softwares, as a feasible teaching aid, essentially for two main reasons:

1) they better provide the stimulus to seek always easier ways in modeling and in approaching a problem;

2) they better highlight the fundamental paradigms of energy conversion, by considering, above all, the main and most frequently transients encountered in energy conversion.

\section{ASPECT OF TEACHING POWER ELECTRONICS AND SOME EDUCATIONAL ISSUES}

It is well known that the simulation of forced commutation converters is easier than that of line commutated converters. For example, in PWM controlled converters the main circuit has a limited number of independent conducting states and configurations. This is less true in the case of a three phase thyristor rectifier where each device operates cyclically depending on the network state and on the previous circuit configuration. Furthermore, if the converter devices are not considered ideal, the current overlapping during commutation contributes to make the thyristors rectifier operation more difficult to understand. In this way the state space modeling of a thyristor converter is quite difficult. This is the reason why thyristor converter simulations encountered in many tutorials and technical papers are made with the help of circuit-oriented tools.

Many times equation-oriented softwares are limited to plotting steady state results, developing well known math formulas, while the circuit and its dynamic behavior remain on the background. For example, in [29] the reconstruction of the thyristors rectifier output voltage is made simply by multiplying a time shifted sawtooth signal and the input voltages. This is an evidently tricky simulation way and takes no account of the real rectifier operating principle. Moreover, it is not able to achieve the simulation of overlapping phenomena.

On the other hand, the simulation which is obtained is very light and computationally fast. In this way the risk of confusion and misunderstanding about the converter real operation is a concrete perspective and reduces simulation resources to the same level of a good textbook.

In this paper, the simulation of a thyristor rectifier has been used by the Authors to show an affordable approach to the problem of teaching power electronics with the support of an equation-oriented simulation software.

A modular teaching approach has been preferred to guide the students step by step at different levels of understanding power conversion. Moreover this approach is useful to guide students towards the creation of concise outlines of complex and articulated systems.

The building block structure of the simulation models hereafter presented allows teachers to create converter topologies of increasing complexity, from simple star rectifiers, to cycloconverters, and allows leaving a plenty of room for personal study of the student, in order to stimulate his curiosity and his interest in the subject.

According to the latest educational guidelines, teaching can not be reduced to a mere data and knowledge transmission. As a matter of fact teaching should induce in the students their personal ability in problem solving and in reworking what they have learned in order to find new solutions for new problems.

This is the reason why a teaching plan must be based on educational goals going beyond the simple contents and notions. Educational goals must be conveyed to students so that they know what is effectively expected by them just from the beginning.

Although educational goal planning is actually adopted in Europe only in high schools and technical colleges, its usage in universities would be beneficial too.

Educational goals are then divided into general and specific ones.

Some general objective could be, for example:

1) to verbalize the choices about the strategies adopted in the problem;

2) to depict graphically the solutions of a problem;

3) to find bounds between physical phenomena and the corresponding mathematical models;

4) to evaluate critically the learning path and the gained knowledge;

Some specific objective could be, for example:

1) to give a brief and clear description of the data and of the unknowns within the assigned problem;

2) to describe employed methodologies;

3) to justify step by step one's choices;

4) to apply a method of solution of the network theory finalized to find the equilibrium equations;

5) to set up computer numerical methods for the solution;

6) to draw the block diagram of a circuit starting from its equations;

7) to identify the significant quantities of the circuit.

Going beyond contents and notions, what is really expected by the students is the development of their self-assessment skills. Self-assessment is the process by which the student gathers information about and reflects on his or her own learning [27], [30].

To realize a such consistent educational system, teachers are required to organize and schedule time, physical space and learning materials so that students can find a suitable learning experience.

Teachers act as advisors to the students, so that they become able to self evaluate their learning processes and to correct them if necessary.

\section{THE EQUATION-ORIENTED SIMULATION SOFTWARE FOR THYRISTORS RECTIFIER}

The simulation tool for thyristor rectifiers has been built in MATLAB because it is a widely used scientific calculation 


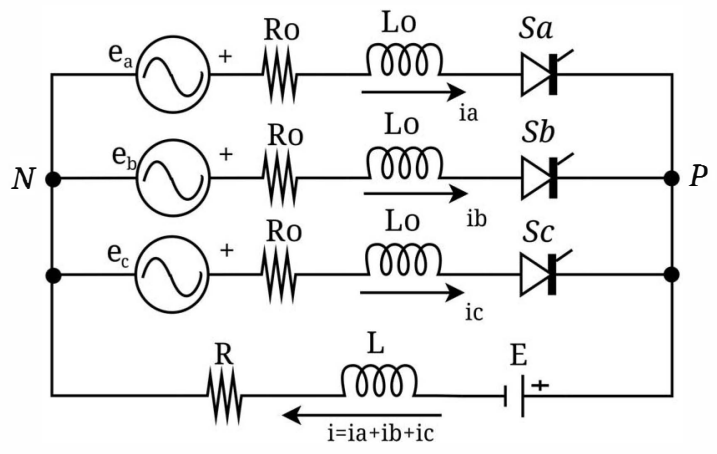

Figure 1. The topology of the star thyristor converter.

software, but any other software with similar characteristic can be chosen. With reference to the topology of the star thyristor rectifier shown in fig. 1 , the differential equations of the circuit are:

$$
\left\{\begin{array}{l}
S_{a}\left(e_{a}-v_{P}-R_{o} i_{a}\right)=L_{0} \frac{d i_{a}}{d t} \\
S_{b}\left(e_{b}-v_{P}-R_{0} i_{b}\right)=L_{0} \frac{d i_{b}}{d t} \\
S_{c}\left(e_{c}-v_{P}-R_{0} i_{c}\right)=L_{0} \frac{d i_{c}}{d t} \\
v_{P}-v_{N}=R \sum_{j \in\{a, b, c\}} S_{j} i_{j}+L \sum_{j \in\{a, b, c\}} \frac{d i_{j}}{d t}+e
\end{array}\right.
$$

where:

$S_{a}, S_{b}$, and $S_{c}$ are the thyristors state variables defined as:

$$
\begin{cases}S_{j}=1 & \text { if the } \mathrm{j} \text {-th thyristor is ON } \\ S_{j}=0 & \text { if the } \mathrm{j} \text {-th thyristor is OFF }\end{cases}
$$

$e_{a}, e_{b}$ and $e_{c}$ are the $\mathrm{AC}$ input voltages;

$v_{P}$ and $v_{N}$ are respectively the potentials of points $\mathrm{P}$ and $\mathrm{N}$; often, for the star converter, it can be assumed that $v_{N}$ is the reference potential, so that $v_{N}=0$;

$i_{a}, i_{b}$, and $i_{c}$ are the the line currents;

$R_{0}$ and $L_{0}$ are, respectively, the resistance and the inductance of the line;

$R$ and $L$ are, respectively, the resistance and the inductance of the load;

$e$ is the load back e.m.f.

Equations (1) describe the behavior of the star thyristor rectifier taking commutation and overlapping phenomena into account. The state variables $S_{j}$ represents the thyristor conduction logic. In particular, they may be written as the following logical function:

$$
S_{j}=\left(v_{A k_{j}}>0\right) \wedge\left(g_{j}=1\right) \vee\left(i_{j}>i_{j H}\right)
$$

where:

$v_{A K j}$ is the anode-cathode voltage of the $\mathrm{j}$-th thyristor;

$i_{j H}$ is the thyristor holding (threshold) current;

$g_{j}$ is the gate firing pulse of the $\mathrm{j}$-th thyristor.

Equation (3) claims that a thyristor conduces when forward biased and if a firing pulse is sent to its gate. It also remain in the ON state until its current is above the threshold value.

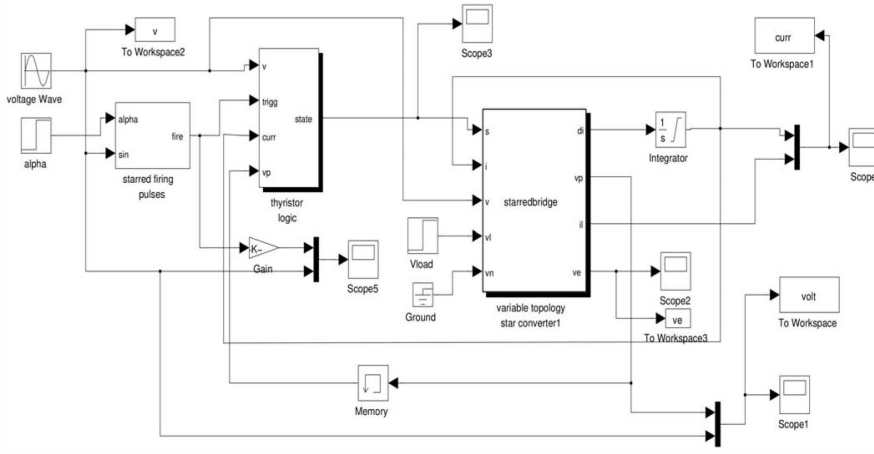

Figure 2. SIMULINK scheme of the Star thyristor converter.

In general $i_{j H}$ is very small, so it could be assumed as null $\left(i_{j H} \approx 0\right)$.

By solving the system with respect to the current derivatives and $v_{P}$ the state equations of the converter can be put in the form:

$$
\left\{\begin{array}{l}
\dot{\mathbf{x}}=\mathbf{A x}+\mathbf{B u} \\
\mathbf{y}=\mathbf{C x}+\mathbf{D u}
\end{array}\right.
$$

where:

$\mathbf{x}=\left[\begin{array}{lll}i_{a} & i_{b} & i_{c}\end{array}\right]^{t}$ is the state space vector (line currents);

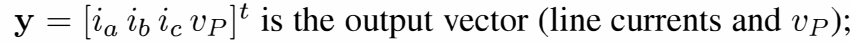

$\mathbf{u}=\left[e_{a} e_{b} e_{c}\left(v_{N}\right)\right]^{t}$ is the input vector (applied voltages and $v_{N}$, eventually if not zero);

$[\mathbf{A}, \mathbf{B}, \mathbf{C}, \mathbf{D}]$ are the four matrices of the state space model. $\mathbf{A}$ is a $3 \times 3$ matrix whose diagonal elements have the form:

$$
a_{i i}=-\frac{S_{i}\left(L_{0} R S_{i}+R_{0} L\left(S_{i+1}+S_{i+2}\right)+L_{0} R_{0}\right)}{L_{0}\left(L \sum_{i} S_{i}+L_{0}\right)}
$$

where the index $i$ must be considered as cyclical. The extra diagonal matrix elements have the form:

$$
a_{i j}=-\frac{S_{i} \cdot S_{j}\left(L_{0} R-R_{0} L\right)}{L_{0}\left(L \sum_{i} S_{i}+L_{0}\right)}
$$

Similar expressions can be found for the elements of the matrices $\mathbf{B}, \mathbf{C}$ and $\mathbf{D}$, but a detailed analysis of them is outside the scope of the paper. It is instead important to remark that all the matrix system coefficients depend on both the circuit parameters and on the thyristor state variables.

The simulation of the star thyristor converter may be realized with the help of a MATLAB embedded function (a particular version of $\mathrm{m}$-code opening with a complete mandatory declaration of variables) in which (4) are implemented to calculate the current derivatives over time. The embedded function is then included in a SIMULINK block scheme (see fig. 2) where the actual currents are calculated via integration of the state space derivatives.

The scheme obviously include the thyristor conduction logic according to (3) and the firing pulse generator synchronized with the supply voltages. Implementing a properly running firing pulse generator could be an interesting exercise for the students. 


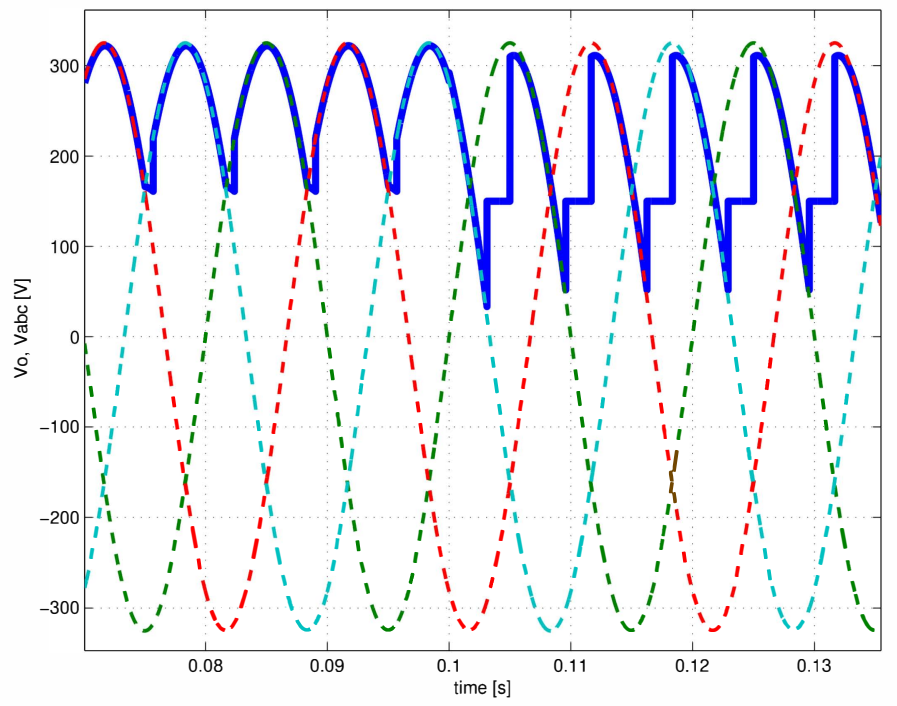

Figure 3. Output (solid line) and input (dashed lines) converter voltages for continuous and discontinuous current conduction mode.

\section{EXAMPLE OF SIMULATIONS}

\section{A. The star thyristor converter}

Some simulations results carried out following the scheme of fig. 2 are hereafter reported. The simulations show the behavior of a star converter feeding a load with constant back e.m.f. with changing firing angle $\alpha$. Initially $\alpha$ is set to zero while it is changed to $\alpha=\pi / 6$ at time $t=0.1 \mathrm{~s}$. The constant load back e.m.f is set to $150 \mathrm{~V}$.

The simulations show that the implemented model is able to reconstruct the operation of the converter both in the cases of continuous and discontinuous current conduction, taking overlapping phenomena into account.

Figure 3 shows, in particular, the input and output voltages versus time.

During the continuous conduction mode the output voltages is composed by the input voltage envelope, except for the commutation intervals, in which it assumes the value $v_{P}=$ $\frac{e_{i}+e_{j}}{2}$ being $e_{i}$ and $e_{j}$ the supply phase voltages undergoing commutation.

During the discontinuous conduction mode the load voltage follows the input voltage, except in the intervals of zero current in which the output voltage is equal to the load back e.m.f. The small difference between input and output voltages is due to the small voltage drop on the line impedance.

Figure 4 shows both the line and the load currents, highlighting also the overlapping phenomenon due to commutation (see also fig. 5 for overlapping simulation detail). No overlapping is, instead, present in the case of discontinuous conduction mode.

Another interesting simulation result is the commutation notch on the supply input voltage (see fig. 6). These notches can produce significant disturbances on the supply network.

These first simulation results are used to present to students some fundamental aspect of the simple star rectifier topology.

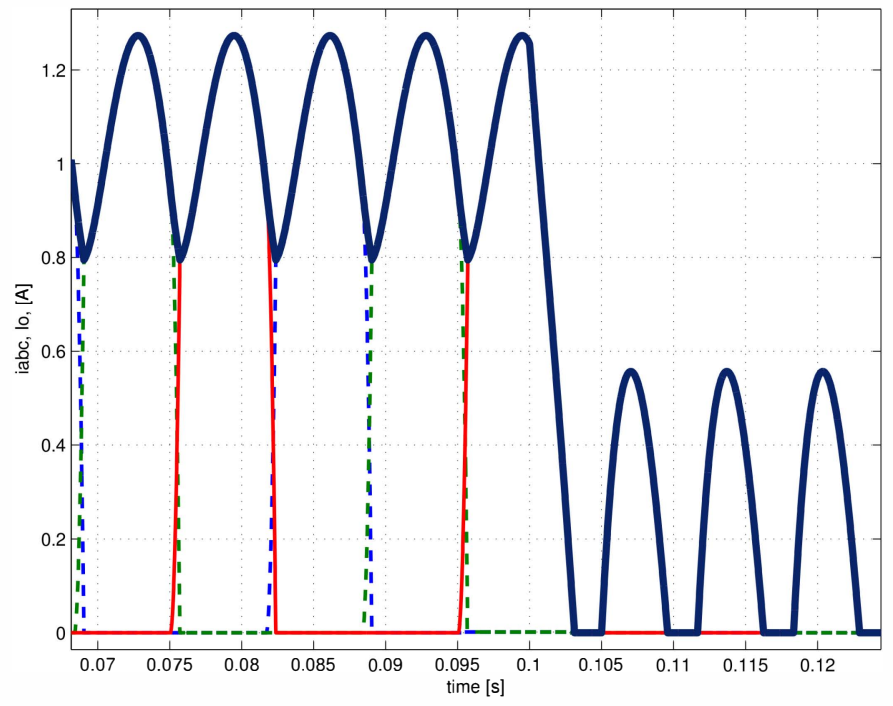

Figure 4. Simulation of the load (blue) and line currents (others) in the star thyristor converter for changing firing angle.

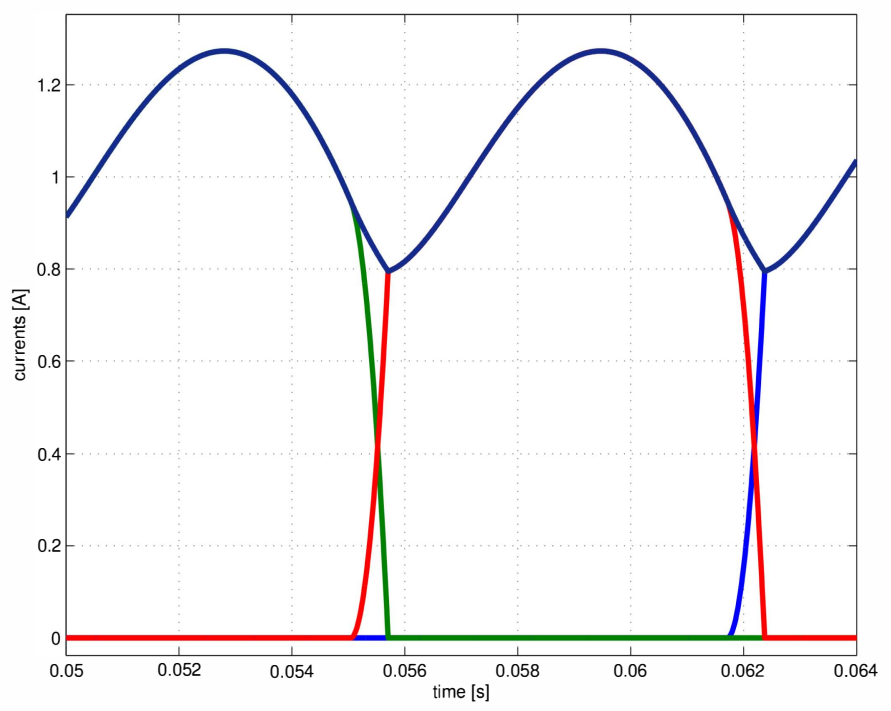

Figure 5. Overlapping of currents (detail)

The students may also consider the differences in the two cases of continuous and discontinuous conduction mode and can check the influence of the different circuit parameters (resistance and inductance of the line, of the load, the change of the load back e.m.f.) on the final results. Students can also verify the change of the commutation time with respect to the firing angle according to the law:

$$
I_{L}=\frac{V_{L L}}{\sqrt{2} \omega L_{0}}[\cos (\alpha)-\cos (\alpha+\mu)]
$$

where $V_{L L}$ is the line to line RMS supply voltage, $\omega$ is its angular frequency, $\alpha$ is he firing angle, $I_{L}$ is the load current and $\mu$ is the overlapping angle, i.e. $\mu=\omega t_{o l}$, being $t_{o l}$ the overlapping time.

It is really important to remark that the presented simulation building block can be re-used to assemble more complex 


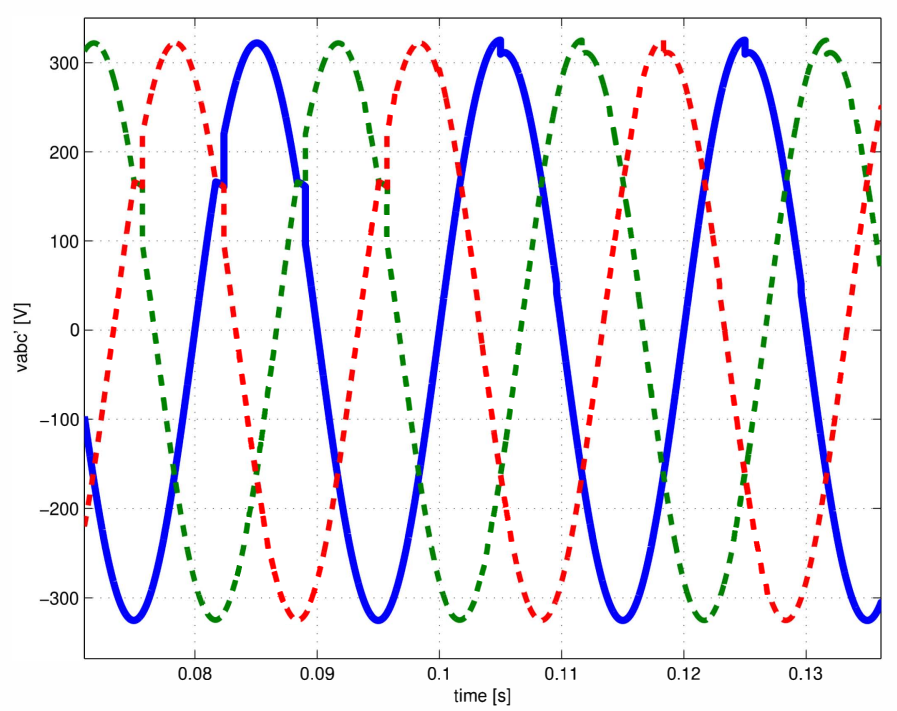

Figure 6. The commutation notch effect on the input voltage with $\alpha$ varying from 0 to $\pi / 6$ at $\mathrm{t}=0.1 \mathrm{~s}$.

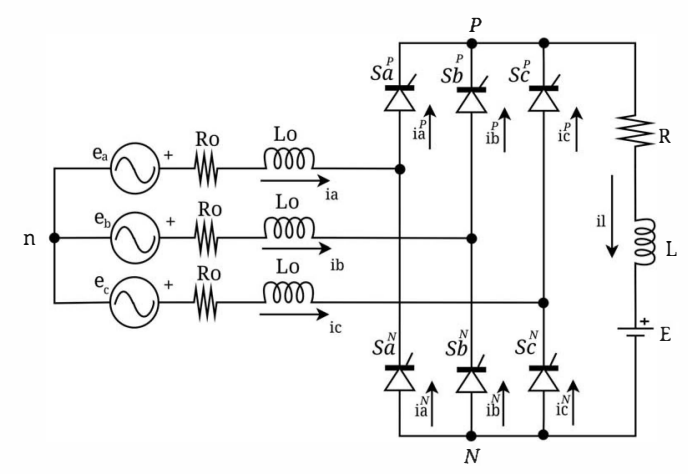

Figure 7. Scheme of the full bridge controlled rectifier.

rectifier topologies as shown in section IV-B.

\section{$B$. The full bridge thyristor converter}

The full bridge controlled rectifier (see fig. 7) can be seen as the assembly of two star thyristor rectifiers conducting the positive current the upper and the negative current the lower.

The significant difference is that now the $v_{N}$ potential is no longer that of the supply network neutral and cannot be assumed zero as before. Finally $v_{P}$ and $v_{N}$ are to be considered as two different outputs in the model.

Equations (1) still apply but with some different meanings. The line currents $i_{a}, i_{b}$ and $i_{c}$ are different from thyristor currents here designated by the superscripts $P$ and $N$, thus for the full bridge converter two sets of differential equations must be written, as follows:

$$
\left\{\begin{array}{l}
S_{a}^{P}\left(e_{a}-v_{p}-R_{0} i_{a}^{P}\right)=L_{0} \frac{d i_{a}^{P}}{d t} \\
S_{b}^{P}\left(e_{b}-v_{p}-R_{0} i_{b}^{P}\right)=L_{0} \frac{d i_{b}^{i}}{d t} \\
S_{c}^{P}\left(e_{c}-v_{p}-R_{0} i_{c}^{P}\right)=L_{0} \frac{d i_{c}^{P}}{d t} \\
v_{P}-v_{N}=R \sum_{j \in\{a, b, c\}} S_{i}^{P} i_{j}^{P}+L \sum_{j \in\{a, b, c\}} \frac{d i_{j}^{P}}{d t}+e
\end{array}\right.
$$

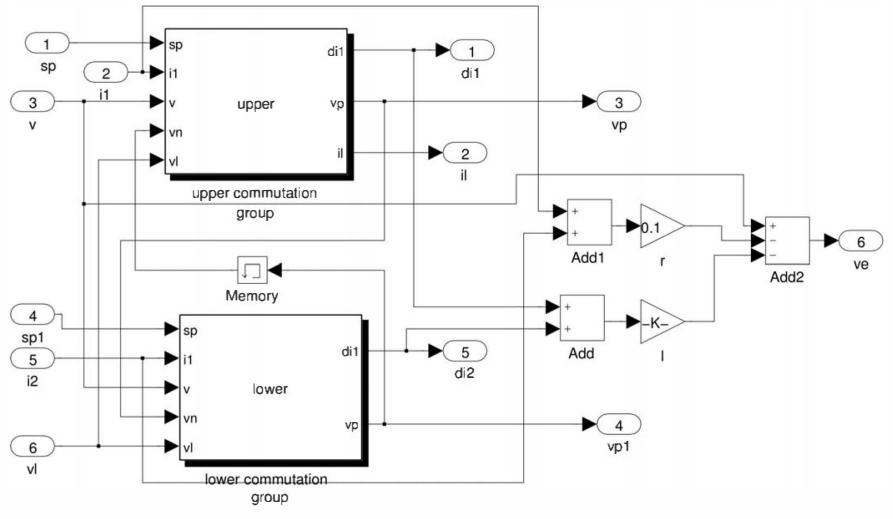

Figure 8. The SIMULINK scheme of the full bridge thyristor rectifier by using the star rectifier blocks.

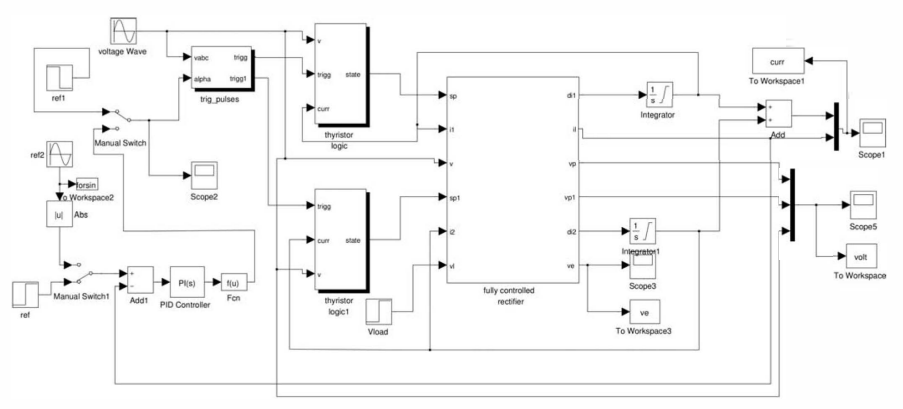

Figure 9. The complete SIMULINK scheme of a full bridge thyristor rectifier.

$$
\left\{\begin{array}{l}
S_{a}^{N}\left(e_{a}-v_{N}-R_{0} i_{a}^{N}\right)=L_{0} \frac{d i_{a}^{N}}{d t} \\
S_{b}^{N}\left(e_{b}-v_{N}-R_{0} i_{b}^{N}\right)=L_{0} \frac{d i_{b}^{N}}{d t} \\
S_{c}^{N}\left(e_{c}-v_{N}-R_{0} i_{c}^{N}\right)=L_{0} \frac{d i_{c}^{N}}{d t} \\
v_{N}-v_{P}=R \sum_{j \in\{a, b, c\}} S_{j}^{N} i_{j}^{N}+L \sum_{j \in\{a, b, c\}} \frac{d i_{j}^{N}}{d t}-e
\end{array}\right.
$$

It is clear that:

$$
i_{a}^{P}+i_{b}^{P}+i_{c}^{P}=i_{a}^{N}+i_{b}^{N}+i_{c}^{N}=i_{L}
$$

thus:

$$
\frac{d i_{a}^{P}}{d t}+\frac{d i_{b}^{P}}{d t}+\frac{d i_{c}^{P}}{d t}=\frac{d i_{a}^{N}}{d t}+\frac{d i_{b}^{N}}{d t}+\frac{d i_{c}^{N}}{d t}=\frac{d i_{L}}{d t}
$$

On the other side, the line currents are:

$$
\left\{\begin{array}{l}
i_{a}=i_{a}^{P}-i_{a}^{N} \\
i_{b}=i_{b}^{P}-i_{b}^{N} \\
i_{c}=i_{c}^{P}-i_{c}^{N}
\end{array}\right.
$$

Equations (10) and (11) can be used to reduce the order of the system, but it is convenient to use the sets (8) and (9) directly as building blocks. According to (8), (9) and (12), the SIMULINK scheme of the full bridge rectifier is then illustrated in fig. 8 where the memory block is used simply to break the algebraic loop. 


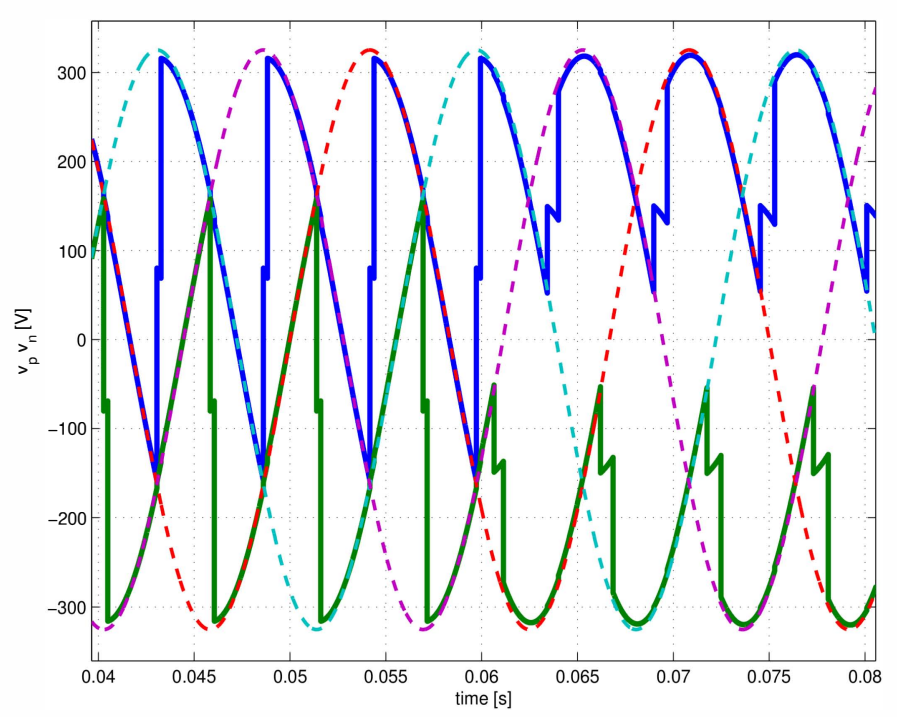

Figure 10. $\quad v_{P}$ and $v_{N}$ potentials (solid lines) and supply voltages (dashed lines).

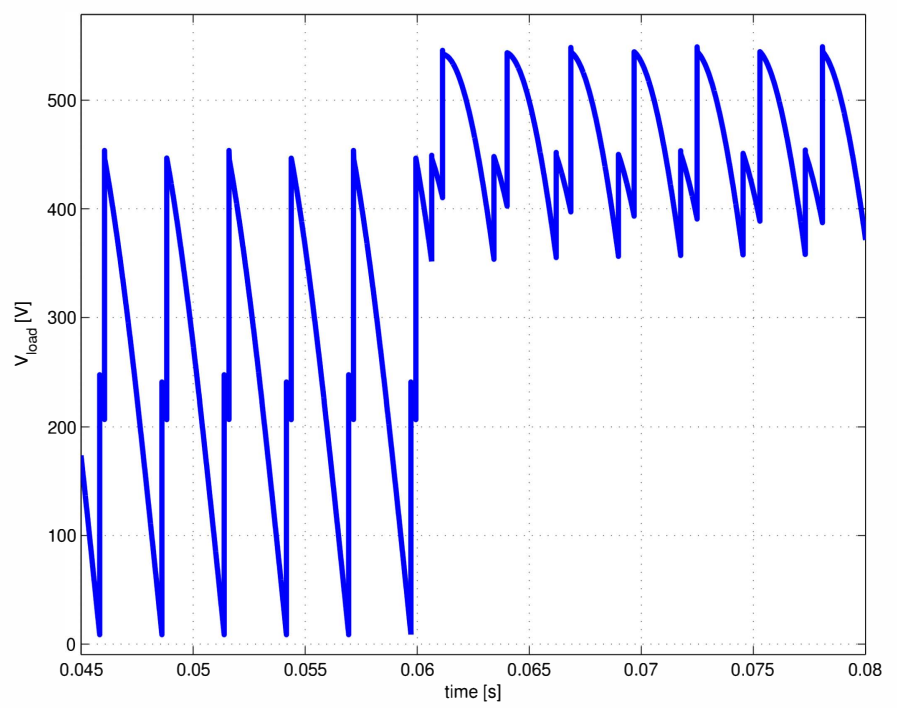

Figure 11. The load voltage with $\alpha$ varying with a step change from 60 to 20 degrees at $\mathrm{t}=0.06 \mathrm{~s}$.

The complete scheme of fig. 9 (in which an optional current control loop is present too), requires the duplication of the thyristor logic conduction block and a full three phase firing pulse generator.

Figures 10-13 show the simulation results carried out for the full bridge rectifier. In particular, they show the potentials $v_{P}$ and $v_{N}$, the load voltage, both the load and the line currents and finally the effect of commutation notches on the input supply voltage, when the firing angle $\alpha$ varies with a step change from 60 to 20 degrees at $\mathrm{t}=0.06 \mathrm{~s}$, with a constant load back e.m.f.

These figures prove that simulations have a very good agreement with the real converter operation.

The same building blocks can be used to create more complex topologies, from bidirectional converters to cyclocon-

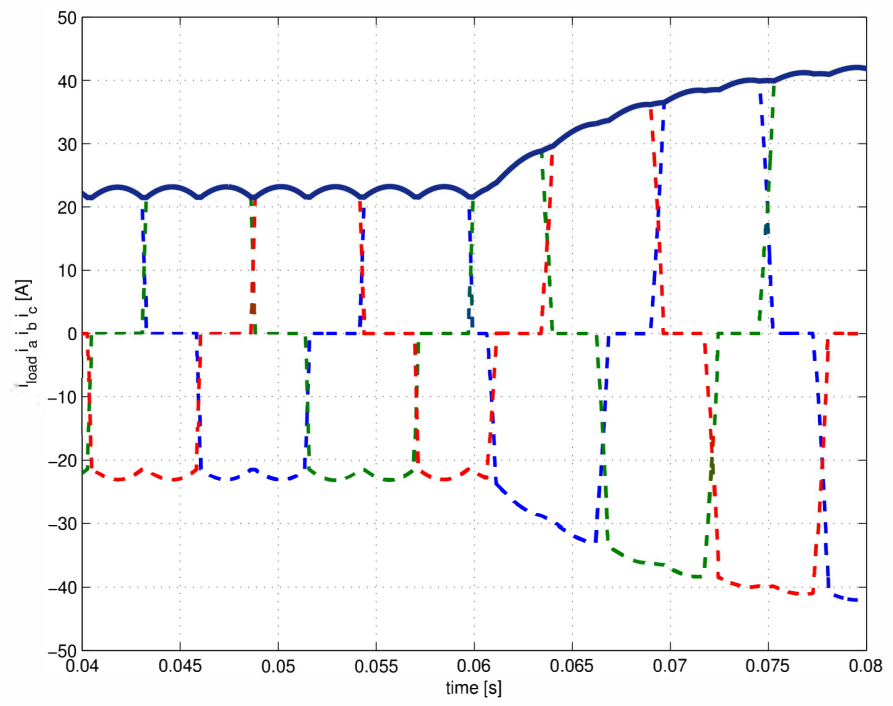

Figure 12. Load (continuous line) and line currents (dashed lines) with $\alpha$ varying with a step change from 60 to 20 degrees at $t=0.06 \mathrm{~s}$.

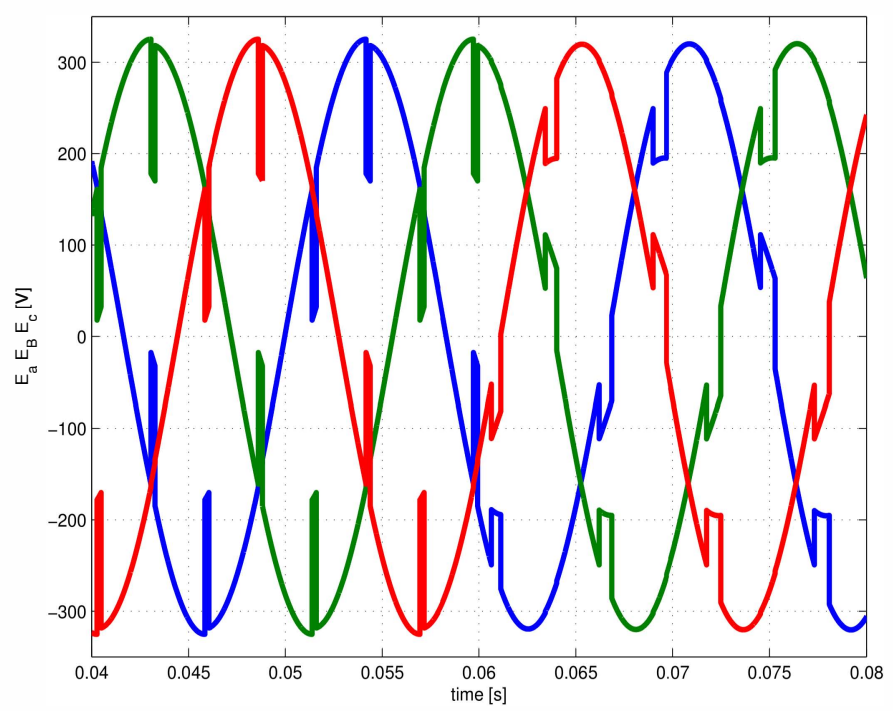

Figure 13. Notch effect of commutation on the supply voltages with $\alpha$ varying with a step change from 60 to 20 degrees at $t=0.06 \mathrm{~s}$.

verters, by simply re-using the star converter block and taking link equations into account. The same approach can be used also for mono-phase rectifiers.

\section{CONCLUDING REMARKS}

Advances in power electronics require necessary adjustments and reconsideration of traditional teaching. On the other hand, the availability of many simulation softwares has changed the teaching paradigm during time. Modern ICT technology led to the concept of learning object as a reliable teaching tool that also allows the student to check his knowledge autonomously all along the training path.

This paper considered a modular approach in teaching power electronics expressly devoted to thyristor rectifiers. A simulator based on MATLAB-SIMULINK has been developed 
to implement the rectifier model through its state equations. Computer programming on the model was based on a suitable building block model regarding the simple three-phase SCR star converter.

The paper has shown how the presented model is able to simulate the different operating conditions of the rectifier, including both the cases of continuous and discontinuous conduction and taking the overlapping phenomenon into account. The simulator thus created includes, in general, all the physical aspects involved in the converter operation, except for the ones related to the physics of individual devices. The scope of a general purpose simulator, but, over all, of a simulator built for didactic purposes cannot be simply plotting realistic pattern for converter voltage and currents, but have to be a tool for a deeper understanding the converter operation.

The developed simulator therefore provides a feasible teaching help to plan specific didactic goals that go beyond a simple transmission of data and knowledge and encouraging selflearning strategies.

\section{ACKNOWLEDGMENTS}

This work has been sustained by the SDESLAB (Sustainable Development And Energy Savings Laboratory) within the University of Palermo

\section{REFERENCES}

[1] P. Stumpf, "Multimedia material for teaching and e-learning in nonlinear dynamics and power electronics," in Industrial Electronics (ISIE), 2010 IEEE International Symposium on, July 2010, pp. 3906-3911.

[2] C. Fernandez, O. Garcia, J. Cobos, and J. Uceda, "Self-learning laboratory set-up for teaching power electronics combining simulations and measurements," in Power Electronics Specialists Conference, 2002. pesc 02. 2002 IEEE 33rd Annual, vol. 2, 2002, pp. 449-454.

[3] D. Lamar, P. Miaja, M. Arias, A. Rodriguez, M. Rodriguez, and J. Sebastian, "A project-based learning approach to teaching power electronics: Difficulties in the application of project-based learning in a subject of switching-mode power supplies," in Education Engineering (EDUCON), 2010 IEEE, April 2010, pp. 717-722.

[4] M. Rashid, "Why, what and how of teaching power electronics," in Power Electronics Systems and Applications, 2004. Proceedings. 2004 First International Conference on, Nov 2004, pp. 16-22.

[5] K. Cheng, C. Chan, N. Cheung, and D. Sutanto, "Virtual laboratory development for teaching power electronics," in Power Electronics Specialists Conference, 2002. pesc 02. 2002 IEEE 33rd Annual, vol. 2 , 2002, pp. 461-466 vol.2.

[6] J. Hudgins, A. Monti, and R. Dougal, "Control system laboratory: a power electronics teaching experience," in Computers in Power Electronics, 2002. Proceedings. 2002 IEEE Workshop on, June 2002, pp. $112-116$.

[7] Y. K. Cheng, K. W. E. Cheng, K. F. Kwok, and T. K. Cheung, "New medium teaching method for power electronics," in Power Electronics Systems and Applications, 2004. Proceedings. 2004 First International Conference on, Nov 2004, pp. 278-283.

[8] L. V. Esther Del Moral-Perez, Ana Cernea, "Connectivist learning objects and learning styles," Interdisciplinary Journal of E-Learning and Learning Objects (IJELLO), vol. 9, pp. 105-124, September 2013.

[9] N. Losic, "Modeling, analysis and simulation of controlled rectifiers with thyristors," in Power Electronics and Drive Systems, 1995., Proceedings of 1995 International Conference on, Feb 1995, pp. 162-167 vol.1.

[10] M. Darwish and C. Marouchos, "Simulation levels in teaching powe electronics," in Power Engineering Conference (UPEC), 2013 48th International Universities', Sept 2013, pp. 1-5.

[11] P. K. Dash, R. Menzies, and R. M. Mathur, "Computer simulation of generator-thyristor networks in power systems," Industrial Electronics and Control Instrumentation, IEEE Transactions on, vol. IECI-27, no. 2 pp. 104-110, May 1980.
[12] S. Eitan and R. Rabinovici, "On line simulation models of electric drives," in Electrical Machines, 2008. ICEM 2008. 18th International Conference on, Sept 2008, pp. 1-6.

[13] D. Nafpaktitis, D. Triantis, P. Tsiakas, C. Stergiopoulos, and K. Ninos, "Using new technologies for teaching power electronics and assessing students," in E-Learning in Industrial Electronics, 2006 1ST IEEE International Conference on, Dec 2006, pp. 125-129.

[14] A. O. Di Tommaso, F. Genduso, and R. Miceli, "A software for the evaluation of winding factor harmonic distribution in high efficiency electrical motors and generators," in Ecological Vehicles and Renewable Energies (EVER), 2013 8th International Conference and Exhibition on, March 2013, pp. 1-6.

[15] A. O. Di Tommaso, F. Genduso, R. Miceli, and G. Ricco Galluzzo, "Computer aided optimization via simulation tools of energy generation systems with universal small wind turbines," in Power Electronics for Distributed Generation Systems (PEDG), 2012 3rd IEEE International Symposium on, June 2012, pp. 570-577.

[16] G. Cipriani, V. Di Dio, L. Di Noia, F. Genduso, D. La Cascia, R. Miceli, and R. Rizzo, "A pv plant simulator for testing mppt techniques," in Clean Electrical Power (ICCEP), 2013 International Conference on, June 2013, pp. 482-489.

[17] V. Di Dio, G. Cipriani, R. Miceli, and R. Rizzo, "Design criteria of tubular linear induction motors and generators: a prototype realization and its characterization," Leonardo Electronic Journal of Practices and Technologies, vol. 12, no. 23, pp. 19-40, 2013.

[18] V. Boscaino, R. Miceli, G. Capponi, and G. Ricco Galluzzo, "A review of fuel cell based hybrid power supply architectures and algorithms for household appliances," International Journal of Hydrogen Energy, vol. 39, no. 3, pp. 1195 - 1209, 2014.

[19] A. O. Di Tommaso, F. Genduso, and R. Miceli, "Analytical investigation and control system set-up of medium scale pv plants for power flow management," Energies, vol. 5, no. 11, pp. 4399-4416, 2012.

[20] F. Viola, P. Romano, R. Miceli, and G. Acciari, "Harvesting rainfall energy by means of piezoelectric transducer," in Clean Electrical Power (ICCEP), 2013 International Conference on, June 2013, pp. 634-639.

[21] F. Genduso and R. Miceli, "A general mathematical model for nonredundant fault-tolerant inverters," in Electric Machines Drives Conference (IEMDC), 2011 IEEE International, May 2011, pp. 705-710.

[22] C. Cecati, F. Genduso, R. Miceli, and G. Ricco Galluzzo, "A suitable control technique for fault-tolerant converters in distributed generation," in Industrial Electronics (ISIE), 2011 IEEE International Symposium on, June 2011, pp. 107-112.

[23] A. O. Di Tommaso, F. Genduso, R. Miceli, and G. Ricco Galluzzo "Experimental validation of a general model for three phase inverters operating in healthy and faulty modes," in Power Electronics, Electrical Drives, Automation and Motion (SPEEDAM), 2012 International Symposium on, June 2012, pp. 50-55.

[24] F. Genduso, R. Miceli, and G. Ricco Galluzzo, "Flexible power converters for the fault tolerant operation of micro-grids," in Electrical Machines (ICEM), 2010 XIX International Conference on, Sept 2010, pp. 1-6.

[25] A. O. Di Tommaso, F. Genduso, R. Miceli, and G. Ricco Galluzzo, "Fault tolerant ancillary function of power converters in distributed generation power system within a microgrid structure,," Advances in Power Electronics, , vol. 2013, pp. 1 - 12, 2013.

[26] G. Cipriani, R. Miceli, C. Spataro, and G. Tine', "Electric power quality evaluation in the presence of electromagnetic emissions," in ICRERA, IEEE, Ed., Madrid, Spain, October 2013, pp. 1 - 6 .

[27] F. Pedone, Valutazione delle competenze $e$ autoregolazione dell'apprendimento. Palumdo Editore, (in italian), 2007.

[28] N. Mohan and O. Schott, "Teaching of first course on power electronics: a building-block approach," in Power Engineering Society Winter Meeting, 2001. IEEE, vol. 2, 2001, pp. 854-855 vol.2.

[29] J. F. Silva, "Computer simulation of generator-thyristor networks in power systems," Revue internationale de genie electrique, vol. 2, no. 1, pp. 7-34, May 1999

[30] J. H. Flavell, "Metacognition and cognitive monitoring: A new area of cognitive-developmental inquiry," American Psychologist, vol. 34, no. 34 , pp. $906-911,1979$. 